\title{
Research on Kohlberg's Theory and Practice in China
}

\author{
Qian Zhang \\ School of English and Education, Guangdong University of Foreign Studies, Guangzhou, China \\ Email: gwzhangqian@126.com
}

How to cite this paper: Zhang, Q. (2018) Research on Kohlberg's Theory and Practice in China. Open Access Library Journal, 5: e4823.

https://doi.org/10.4236/oalib.1104823

Received: August 2, 2018

Accepted: August 28, 2018

Published: August 31, 2018

Copyright (c) 2018 by author and Open Access Library Inc.

This work is licensed under the Creative Commons Attribution International License (CC BY 4.0).

http://creativecommons.org/licenses/by/4.0/

\begin{abstract}
Since 1980s Kohlberg's theory of moral cognitive development has great influences on Chinese moral education. The Chinese scholars introduced Kohlberg's theory into China and made some theoretical comments first and then made some empirical research in Chinese schools and universities. More and more empirical and cross-cultural research results jointly made by both Chinese and Western scholars have been published since the beginning of the new century. Post-Kohlberg theories began to be introduced into China, such as DIT, MJT and Social cognitive domain theory and so on. All of these theories have important enlightenment on Chinese moral education and facilitate the reform and innovation of the Chinese moral education to some extent. There are still some arguments with Kohlberg and post-Kohlberg theories in the empirical research made by Chinese scholars and so more research should be needed in the future.
\end{abstract}

\section{Subject Areas}

Education, Linguistics

\section{Keywords}

Kohlberg, Moral Cognition and Development, Chinese Moral Education

\section{Introduction}

Lawrence Kohlberg (1927-1987) is a well-known child psychologist, educator and moral philosopher and he is also the creator of the school of moral cognition and the main representative of moral cognitive development in Western countries. Since Piaget in 1932 advocated the theory of moral development stages in his book Moral Judgment of Children, Kohlberg inherited and further developed Piaget's theory to make his own research on children's moral cognition 
development for about 30 years. In 1960s Kohlberg proposed his model of moral development stage which is known as "three levels and six stages" and founded a theoretical system for moral cognitive development and education based on the model. It is due to his creative contribution to modern theory of moral cognitive development and practice of moral education that has broad influence on the academic world education in many countries among which China's moral education is influenced greatly within resent 30 years.

The research on Kohlberg and his theory in China started from 1980s and up to now it has lasted for about 30 years. The main research products include the translation of Kohlberg's works and some other related articles as well as the theoretical and empirical research based on his theory that could be divided into the following three parts.

\subsection{The Introduction to Kohlberg's Theory}

The Chinese scholars translated Kohlberg's original works into Chinese since 1980s, including Moral Development and Moral Education translated by Dongxing Wu [1], The Philosophy of Moral Education translated by Xianchao Wei [2] and Psychology of Moral Development. The Nature and Validity of Moral Stages translated by Guo Benyu and his colleagues [3].

\subsection{The Theoretical Comments on Kohlberg's Moral Cognitive Development Theory}

The theoretical research on Kohlberg's ideas including Benyu Guo's translated work entitled Moral Cognitive Development and Moral Education-Kohlberg's Theory and Practice [4], Shaogang Yang's Psychology of Moral Education and A New Development of Western Moral Psychology [5] that have some theoretical comments on Kohlberg's moral psychology. Many commentary articles on Kohlberg's theory have been published such as "A comment on Kohlberg's stage theory of moral cognitive development" [6], "From heteronomy morality to autonomy morality-A commentary introduction to Kohlberg's moral theory of types" [7] and so on. It is counted that over 100 articles on Kohlberg's theory have been published in the past 30 years. Huichang Chen has also published his book entitled Psychology of Moral Development [8], in which some comments on Kohlberg's theory and post-Kohlberg's ideas are made.

\subsection{The Empirical Research and Practice of Kohlberg's Theory}

The Chinese scholars made some empirical research on Kohlberg's strategy of moral education such as "A tentative analysis on the experimental research of Kohlberg's 'Just Community" [9], “A commentary introduction to the measurement of moral cognition" [10], "Defining issue test and Neo-Kohlbergian theory" [11]. Kohlberg's students and followers such as D. Boyd and M. L. Arnold and C. Helwig also made some empirical research together with the Chinese scholars. Up to now it has lasted for over 10 years. Some of the results have 
been published, for example, "Chinese adolescents' reasoning about democratic and authority-based decision making in peer, family, and school contexts" [12], and "Urban and rural Chinese adolescents' judgments and reasoning about personal and group jurisdiction" [12].

Generally speaking, there are two main features for the research of Kohlberg's moral education theory in China: firstly, the research of the Chinese scholars on Kohlberg's theory of moral cognitive development have been increasing rapidly, and especially in recent 10 - 15 years, more and more empirical and cross-cultural research results jointly made by both Chinese and Western scholars have been published; secondly, Chinese scholars' interest has been changed from Kohlberg's theory and practice to post-Kohlberg's theory and moral education, such as Defining Issue Test created by J. Rest and his colleagues, Moral Judgment Test developed by German psychologist G. Lind. The social cognitive domain theory advocated by E. Turiel has also been paid more and more attention by Chinese scholars [13].

\section{The Enlightenment of Kohlberg's Theory on Chinese Moral Education}

The Chinese moral education has a very long cultural tradition that has been lasted for over 5000 years. The present Chinese moral education since 1949, however, is actually a so-called "large moral education" [14], that includes political education, ideological education, values education, civic education and even includes mental education, physical training and labor education and so on. Strictly speaking, the contemporary China has no special curriculum of "moral education" in the sense of Western understanding. After the Cultural Revolution in 1976 and especially since the implementation of the reform and open policy since 1978, more and more scholars recognized that such "large moral education" has very low effect on the students' moral development. From 1980s Kohlberg's theory of moral cognitive development began to be introduced to China and many Kohlbergians came to China to give lectures on Kohlberg's theory and moral education and also began to have some empirical researches in China, the results of which have some profound impact on Chinese moral education. The following aspects are the enlightenment of Kohlberg's theory on Chinese moral education.

\subsection{Moral Education Should Cultivate and Develop Students' Moral Judgment Competency}

In Chinese moral education the values of a moral subject are not sufficiently recognized and therefore the values from government or some authorities would be usually imposed to a moral subject such as a student in the school or a child in the family or even a staff in the organization. Kohlberg pointed out that moral education is never the recitation of moral rules or forced discipline, because moral development occurs through a natural sequence of stages; therefore, their approach defines the aim of moral education as "the stimulation of the next step 
of development" [15]. The competency of moral judgment is the center of moral cognition and therefore only when a child can tell right from wrong according to his own moral judgment can it be said whether a child has low or high levels of moral development. The traditional Chinese moral education usually requires a teacher to tell his or her students what is right or wrong according to the textbook or a teacher's understanding. At the end of the semester the students have to take part in the paper examination in which many knowledge contents are included. The students have to recite what they learned during the semester or from the textbook to pass the examination that is actually the measurement of a student's memory but not the real level or competency of moral judgment.

Since the beginning of the 21 century, the Chinese moral education has made a reform, especially in the primary and secondary schools. That moral education should "return to life" has become a value approach of the Chinese moral educational reform in 21 century. Prof. Jie Lu in Nanjing Normal University acted as one of the top leaders of the present Chinese moral education. She advocated that "The root of moral education is actually in the authentic education. It could both teach students to get the methods and skills for their existence and guide people to acquire the significance and values for existence. It makes people either know on what they depend to live or know why they are alive, so as to possess the significant world special for human beings. Education, moral education has played important parts in constructing people's significant world. Modern education has shown a tendency to return to its original nature" [16]. Through this curriculum reform the Chinese moral education in the primary schools has changed their curriculum and textbooks from political and ideological education to Moral Character and Life in the first and second grades and Moral Character and Society for the students from Grade 3 - 6. The contents of the textbook are more life styled and more and more discussions are introduced to the classroom by means of which students' moral judgment competency should be facilitated and raised.

\subsection{The Traditional Classroom Teaching Methods Should Be Innovated in Chinese Moral Education}

The traditional Chinese moral education usually treats students as pure receivers of a certain moral values and therefore teachers used to tell students what they should do. But the students trained in this educational system would be necessarily lack of creativity, independency and autonomy; on the contrary they would have blind obedience and lose their own autonomous personality. According to Kohlberg, the moral conflict stimulated by moral dilemma could make a student to choose a certain behavior in accordance with his or her moral judgment. Only when a child has some moral conflict can he or she make some choices according to his or her moral judgment. And thus in the classroom the students' morality could be developed only through the classroom discussion of some moral dilemmas because it could raise the moral conflict in children's mind to promote them to make their own moral judgment. The research of 
moral psychology has approved that conflict is helpful to the moral learning of students [17].

Kohlberg regarded the idea that "It must raise among students the true moral conflict and different opinions" as one of the three principles of moral education methods and therefore he proposed the dilemma discussion method that makes some scenarios to invoke the moral conflict in which the moral questions are asked in order for students to answer. The students have to "project" their inner ideas within their mind that reflect their own levels and stages of moral development. This kind of method has been proved to be practicable and feasible [18]. For example, in the present primary school textbooks published by Jiangsu Education Press, the main themes of each course appear in the form of topics and its contents include the dialogue between students and text, among students and between students and teachers, so that the design of students' subjectivity and mutual interaction of teachers and students effectively guide a teacher to change his or her role from commanding authority to an equal participant.

\subsection{Moral Cognition Development Should Be the Center of Moral Education}

In traditional Chinese moral education, people usually paid much attention to the combination of children's moral cognition and behavior with the emphasis on the latter. However, the moral cognition has been changed into the so-called moral knowledge in which the people can recite the ancient axioms but do not necessarily follow such teachings in their behavior. In other words, people's moral cognition does not develop correspondently with their knowledge because they seldom make any moral judgment according to some law. What they have to listen to and obey is what an authority or government official said. More and more scholars in present China has recognized the drawbacks of such moral education and suggested [19] that moral education in China should promote students' subjective construction, improve their structure of moral cognition, refine their level of moral behavior to develop their moral qualities, and refuse the overriding concern for the teaching and instilling of moral knowledge without any moral judgment and reasoning.

First of all, the two conceptions of moral cognition and moral knowledge need to be differentiated, the focus of the former is on the moral judgment and reasoning and therefore students have to think deeply and make their own moral judgment according to their moral values. However, the moral knowledge focuses mainly on the recitation of some rules and norms and principles without any profound exploration of the implications within the knowledge. What it examines is actually a person's memory but not the real thinking. From this differentiation it can be said that moral cognition is much more important than the moral knowledge, and thus the moral discussion should become one of the major method in classroom moral education.

Secondly, moral cognition could promote a person to behave in consistence with his moral judgment to a large extent, although it could not determine all 
the behavior. Moral behavior directly depends on one's moral choice which is based mainly on one's moral judgment. As it is well known, moral behavior is a kind of responses to a certain situation on face of which a person should have to define and interpret it according to his or her standard of moral judgment that is actually one's moral criteria or values [20]. Using the moral dilemma to induce discussion among students is actually to create a situation for students to make their own judgment, and through their discussion they could probably clarify some of their confused understanding and raise their competency of moral judgment. However, it need to be noted that such moral competence is "the capacity to make decisions and judgments which are moral (i.e., based on internal principles) and to act in accordance with such judgments" [21], that did not notice the deviation between knowledge and action. Lind's MJT has solved such problem to some extent, as it measures both moral orientation (the moral affection) and moral competence. As Lind said, "moral orientations are-under normal conditions-highly correlated with moral judgment competence: the higher an individual's ability to apply their moral orientations to decision-making the more they prefer principled moral reasoning and the more they reject pre-conventional (that is, low-stage) reasoning" [22]. And so in moral education it can be suggested to create some situations in which the students affection and cognition could be mobilized and the moral discussion about the situation could raise their real moral judgment competence so that their cognition could be connected with their action tightly.

\section{New Research on Post-Kohlberg's Theory of Moral Cognitive Development and Some Reflections}

With the development and deepening of the research in China, since 1990s more and more Chinese scholars noticed the development of post-Kohlberg theories and moral education in Western countries, especially in the US. The new approaches in this field at present Chinese moral education can be summarized as follows.

\subsection{The Research of DIT in China}

Defining Issues Test (DIT) is a new developed moral measurement devised by James Rest in 1979 in the University of Minnesoda that is still in its continuous revision and development up to now. The earliest scholars who made their research by using DIT in China are the following.

Xin Ling Wang in 1987 used DIT1 and Rocket's instrument of Values to make an empirical research in order to investigate the features of high school students' value system and moral development as well as the correlation between them. The results show that the second grade in Junior high school is the key period of the students' moral judgment that is strongly dependent on their values. Xinyin Chen is the earliest to introduce DIT into China and translate it into Chinese, and she and Yu Xiang [23] used DIT to make an empirical research the results of 
which shows that the development of moral judgment is mainly correlated with education but not with ages. And it also finds that the students' levels of moral judgment have some relation to the development of the local economy and culture, the students' learning achievements and peer relationship and so on.

Since the beginning of the 21 century more and more people started to do the research by using DIT. Fang Ding's researches [24] found that there is interaction among children's moral judgment, moral empathy and prosocial behavior; children's prosocial behavior with high level of moral judgment is more clearly influenced by empathy than the children with low levels of moral judgment and vice versa for the children with high levels of empathy.

Shaogang Yang and his student Huihong Wu [25] [26] made the theoretical comment on the new development of DIT2 and published such articles as "DIT and the research on moral evaluation-A new development of Kohlberg's theory" and "DIT and the analysis on the structural elements of morality" that made a profound introduction to DIT2. And he also supervised his student Xiujuan Sun [27] to make an empirical research by using DIT2 and completed a master thesis entitled A Psychological Research on Defining Issues Test 2. This is the first empirical research with DIT2 in mainland China.

Besides the research by the scholars in mainland China, the scholars in China's Hong Kong, Macau and Taiwan also make a series of researches by using both DIT1 and DIT2. For example, Hing-Keung Ma [28] translated DIT1 into Chinese in Hong Kong and used among the students there to prove Kohlberg's stage theory. And Ma made a further comparative research in China's Hong Kong, some mainland area of China and England. The results also support Kohlberg's stage theory but there are some cultural differences in the understanding of stage 4. Ma and his colleagues made some further researches [29] by using the participants from China's Hong Kong, England and the United States, and the results are nearly the same as it was in 1988.

Hong Kong scholar Irene Hau-Siu Chou [30] and his colleagues made an empirical research on the relationship between MBA students' structure of moral stages and their ways of solving the conflicts. The results show that it has close relationship in both Hong Kong students and mainland students. The most recent research of DIT2 in China was made by Chinese scholars Yi-Hui Ho and Chieh-Yu Lin who made a research in Chinese Taiwan on the relationship of student's cultural values and their moral cognitive development among the Chinese Taiwan's students and those of American [31]. The findings pointed out the important impact of the cultural values on student's moral development. The following research [32] the two authors used DIT2 to make an analysis on the moral reasoning competence of the purchasing manager in both China's Taiwan and mainland. The results found that their scores on conventional level in the two areas are both higher than those in post-conventional level, that is, the people in these two areas are both influenced by Chinese culture but the scores of the managers in China's Taiwan is a little bit higher than those in mainland 
China.

All the above research has much enlightenment on Chinese moral education and has made us deeply reflect on some implications of people's moral development. Some questions have been asked by the scholars in China and the world as following.

\subsection{People's Morality Is Developed in Sequence, but Are All the Stages Proposed by Kohlberg Universal?}

According to Kohlberg's theory of moral development, people's morality develops along a series of 3 levels and 6 stages that have been demonstrated widely valid and universal and have nearly no cross-cultural differences by many researches [33] [34] [35]. However, these so-called conclusions are confronted with many challenges in Chinese empirical researches in recent 10 - 20 years.

Some research has found that the moral reasoning of Chinese children matured earlier than that of American children in their teenage years, but their moral development in stage 4 and 5 was slower than that of American children [36]. As for the reasons, more researches are still needed and therefore it could not be regarded as the final conclusion. Moreover, the Chinese scholars in Taiwan also used Kohlberg's method to make a long-term empirical research [37] that found it is very difficult to analyze the moral reasoning of many Chinese participants by using Kohlberg's scoring system. Perhaps it has some cultural differences for the understanding of Kohlberg's dilemmas that are mainly based on Western culture. Another Chinese scholar Ma [38] proposed a developmental model of moral judgment by using the Defining Issues Test and integrating Piaget's, Kohlberg's, as well as jointing the Chinese perspectives on moral development based on Confucianism and Taoism as well as Buddhism. His research conclusion is that the first three stages were universal, but the final three stages of moral development were influenced by cultural contexts. And therefore some doubts are raised whether Kohlberg's theory of three levels and 6 stages are universal or need more empirical research and revision.

\subsection{Are There Gender Differences in Chinese People's Moral Development?}

Feminist criticized that Kohlberg's theory focuses too much on the justice and right orientations that are mainly characteristic of male. In the United States [39] proposed that feminine morality emphasizes an "ethic of care" that Kohlberg's theory devalues. According to her tend to stress care and empathic perspective-taking because of their more experience as caregivers. The Chinese scholars [40] theoretically criticized such idea and they proposed that "care" is a common attribution both male and female have that could eliminate the moral orientation and gender differences. Many other Chinese scholars write their own articles to criticize such idea but most of the papers are based on theoretical or philosophical foundation and have less empirical researches. However, Qiang Xing [41] made an empirical research with some dilemma stories as instrument 
that found that there are consequentialism and non-consequentialism moral reasoning style in human moral judgment; in certain far-fetched hypothetical moral dilemmas there are some gender differences, but for the most part, moral judgment in men and women is extremely similar. Generally speaking, more empirical and deep researches are needed to find whether there are gender differences in people's moral judgment and moral development.

\section{Conclusion}

Kohlberg's theory of moral cognitive development has elaborated the regular pattern of moral development, which has enlightened moral education both in the West as well as China. After its birth, there have emerged lots of theoretical and empirical researches, which prove their universality across cultures and also promote their development. In the latest 30 years, post-Kohlberg theories develop rapidly, but there are some arguments with Kohlberg and post-Kohlberg theories in the empirical research made by Chinese scholars and so more research should be needed in the future.

\section{Conflicts of Interest}

The authors declare no conflicts of interest regarding the publication of this paper.

\section{References}

[1] Peters, R.S. (2000) Moral Development and Moral Education. Zhejiang Education Publishing House, Hangzhou.

[2] Kohlberg, L. (2000) Philosophy of Moral Education. Zhejiang Education Publishing House, Hangzhou.

[3] Kohlberg, L. (2004) Psychology of Moral Development: The Nature and Validity of Moral Stages. Huadong Normal University Publishing House, Shanghai.

[4] Kohlberg, L. (1999) Moral Cognitive Development and Moral Education-Kohlberg's Theory and Practice. Fujian Education Publishing House, Fuzhou.

[5] Yang, S.G. (2007) Psychology of Moral Education and a New Development of Western Moral Psychology. Shanghai Education Publishing House, Shanghai.

[6] Feng, Z. (1990) A General Perspective of Kohlberg's Stage Theory of Moral Cognitive Development. References of Foreign Education, 1, 25.

[7] Guo, B. (1999) From Heteronomous Morality to Autonomous Morality: A Commentary Introduction to Kohlberg's Theory of Moral Types. Journal of Nanjing Normal University, 5, 65.

[8] Chen, H.C. (2004) Psychology of Moral Development. Anhui Education Publishing House, Hefei.

[9] Deng, C. (1993) A Tentative Analysis on the Experimental Research of Kohlberg's "Just Community". Educational Research and Practice, 4, 69.

[10] Guo, B. (1994) A Commentary Introduction to the Measurement of Moral Cognition. Educational Theory and Practice, 5, 74.

[11] Yang, S. (2006) Defining Issue Test and Neo-Kohlbergian Theory. Ideological and 
Theoretical Education, 4, 29.

[12] Helwig, C., Arnold, M.L., Tan, D. and Boyd, D. (2003) Chinese Adolescents' Reasoning about Democratic and Authority-Based Decision Making in Peer, Family, and School Contexts. Child Development, 74, 783-800. https://doi.org/10.1111/1467-8624.00568

[13] Helwig, C.C., Yang, S., Tan, D., Liu, C. and Shao, T. (2011) Urban and Rural Chinese Adolescents' Judgments and Reasoning about Personal and Group Jurisdiction. Child Development, 2, 701-716. https://doi.org/10.1111/j.1467-8624.2010.01531.x

[14] Tan, C. (2003) The Principles of Moral Education in Schools. Educational Science Press, Beijing.

[15] Kohlberg, L. and Turiel, E. (1971) Moral Development and Moral Education. In: Kohlberg, L., Ed., Collected Papers on Moral Development and Moral Education, Moral Education \& Research Foundation, Harvard University, Cambridge, 410-465.

[16] Lu, J. (2002) The Returning to Authenticity of Education. In: Zhu, X., Ed., A Commentary Series of Moral Education, Nanjing Normal University Press, Nanjing, 47-59.

[17] Smetana, J., Killen, M. and Turiel, E. (1991) Children's Reasoning about Interpersonal and Moral Conflict. Child Development, 62, 626-644. https://doi.org/10.2307/1131136

[18] Yu, S. (2010) A Consideration of Students' Autonomy in Moral Education for University and Colleges. Journal of Hubei Economic College, 3, 35.

[19] Wan, Z. (2013) The Theory of Individuals' Moral Cognition Development and Its Enlightenment on Moral Education in Schools. Education and Teaching Research, 27, 67-81.

[20] Blasi, A. (1983) Moral Cognition and Moral Action: A Theoretical Perspective. Developmental Review, 3, 178-210. https://doi.org/10.1016/0273-2297(83)90029-1

[21] Kohlberg, L. (1964) The Psychology of Moral Development: Essays on Moral Development. Vol. 2, Harper and Row, San Francisco.

[22] Lind, G. (2006) The Cross-Cultural Validity of the Moral Judgment Test: Findings from 29 Cross-Cultural Studies. The American Psychological Association (APA).

[23] Chen, X. and Xiang, Y. (1990) Development of Adolescents' Moral Judgment Competency and the Influencing Factors in China. Correspondence of Psychological Science.

[24] Ding, F. (2000) The Relationship of Children's Moral Judgment, Empathy and Prosocial Behaviors. Journal of Shandong Normal University, 9, 17.

[25] Yang, S.G. (2003) What Is a Moral Person: A Challenge Contemporary Psychology to Kohlberg. Educational Theory and Practice, 4, 65.

[26] Yang, S. and Wu, H. (2004) Defining Issues Test and Research of Moral Evaluation: A New Development of Kohlberg's Theory. Contemporary Educational Science, No. $17,56$.

[27] Sun, X. (2005) Psychological Research on DIT-2. Master's Thesis. http://kns.cnki.net/KCMS/detail/detail.aspx?dbcode=CMFDanddbname=CMFD20 07andfilename $=2007108072$.nhanduid $=$ WEEvREcwSlJHSldRa1FhcEE0NXdo

[28] Ma, H.-K. (1988) Objective Moral Judgment in Hong Kong, Mainland China, and England. Journal of Cross-Cultural Psychology, 19, 78-95. https://doi.org/10.1177/0022002188019001006 
[29] Ma, H.-K. (1989) Moral Orientation and Moral Judgment in Adolescents in Hong Kong, Mainland China and England. Journal of Cross-Cultural Psychology, 20, 152-177. https://doi.org/10.1177/0022022189202003

[30] Chou, I.H.-S. and Ding, D.Z.Q. (2002) Moral Judgment and Conflict Handling Styles among Chinese in Hong Kong and PRC. Journal of Management Development, 21, 666-679.

[31] Ho, Y.-H. and Lin, C.-Y. (2009) Cultural Influences on Moral Reasoning Capacities of Purchasing Managers: A Comparison across the Taiwan Strait. Social Behavior and Personality: An International Journal, 37, 203-208.

[32] Ho, Y.-H. and Lin, C.-Y. (2016) The Moral Judgment Relationship between Leaders and Followers: A Comparative Study across the Taiwan Strait. Journal of Business Ethics, 134, 299-310. https://doi.org/10.1007/s10551-014-2431-1

[33] Colby, A., Kohlberg, L., Gibbs, J.C. and Lieberman, M. (1983) A Longitudinal Study of Moral Judgment. Monographs of the Society for Research in Child Development, 48, 124. https://doi.org/10.2307/1165935

[34] Page, R.A. (1981) Longitudinal Evidence for the Sequentiality of Kohlberg's Stages of Moral Judgment in Adolescent Males. Journal of Genetic Psychology, 139, 3-9. https://doi.org/10.1080/00221325.1981.10533431

[35] Walker, L.J. (1989) A Longitudinal Study of Moral Reasoning. Child Development, 60, 157-166. https://doi.org/10.2307/1131081

[36] Kuang, K.-K. (2012) Foundations of Chinese Psychology: Confucian Social Relations. Springer Science and Business Media, Berlin, 141.

[37] Cheng, S.W. (1991) A Cross-Cultural Investigation of Research on the Development of Moral Judgment. In: Yang, C.F. and Kao, H.S.J., Eds., Chinese People and Chinese Mind, Yuan Liu, Taipei, 213-304. (In Chinese)

[38] Ma, H.-K. (1992) The Moral Judgment Development of the Chinese People: A Theoretical Model. Philosophica, No. 49, 55-82.

[39] Gilligan, C. (1982) In a Different Voice: Psychological Theory and Women's Development. Harvard University Press, New York.

[40] Liu, C. and Cheng, S. (2012) Do Moral Judgment Orientation Really Have Gender Differences? Some Empirical Doubts from Psychology. Shanghai Educational Scientific Research, No. 12, 24-26.

[41] Xing, Q. (2005) On the Sex Differences in Moral Judgment. Psychological Exploration, No. 4, 67-69. 